\title{
Method for improving of activated sludge drying by the appropriate foaming pre-treatment
}

\author{
Xue $\mathrm{Li}^{1}$, Yining $\mathrm{Hu}^{1}$, Liang Chen ${ }^{2 a}$, Yuhao Song ${ }^{1}$, Renguo Liu ${ }^{1}$, Can $\mathrm{Yu}^{1}$ \\ ${ }^{1}$ College of Biological and Environmental Engineering, Changsha University, ChangSha 410022, China \\ ${ }^{2}$ Hunan Research Academy of Environmental Sciences, Changsha, Hunan, 410004, China
}

\begin{abstract}
Due to the high viscosity and stickiness of dehydrated sludge, the combination of foaming pretreatment and drying process is an effective method to improve the drying performance of dehydrated sludge. In this study, alkali and industrial lignin fiber addition followed by mechanical whipping was employed for foaming the dewatered sludge. Using alkali alone as foaming agent, the optimal $\mathrm{NaOH}$ addition was found at $2.5 \mathrm{wt} \%$, which was superior to adding $\mathrm{CaO}$. Considering the maximum foaming efficiency, $2 \%$ industrial lignin fiber FH-300 collected as a conditioner and 1\% $\mathrm{NaOH}$ was optimal. The foams in dewatered sludge were highly stable. The total number of bubbles of sludge with different densities had big differences. The diameters of bubbles concentrated on the range of $0.1 \mathrm{~mm}-0.3 \mathrm{~mm}$.
\end{abstract}

\section{Introduction}

In recent years, with the increase of urban sewage treatment rate, the amount of sludge produced in sewage treatment process also increases sharply. If a large amount of sludge is not properly treated and disposed, it will cause great pollution and harm to the natural environment[1]. In process of sludge treatment and disposal, water content is an important parameter to measure the properties of sludge. The water content of residual sludge in general urban sewage treatment plants is as high as $99.2 \%$, but the final disposal of sludge usually requires less than $50 \%$. Thermal drying technology is the most widely used, which realize the rapid dewatering of sludge. In order to obtain thermal drying efficiency with lower treatment cost as well as systematic optimization and mechanism study of the established drying process, it is necessary to make improvement from external conditions, such as pretreatment of sludge[2-4].

Foam-mat drying is a process by which a liquid or semiliquid is whipped by various means to form a stable foam, and then dehydrated by evaporation of water. Foaming treatment can effectively increase the contact area between the material and the drying medium. It also can improve the moisture transfer ability in the material through the foam liquid film, the drying rate of the material, which is suitable for the difficult drying materials with high thermal sensitivity and viscosity[5]. And the dehydrated sludge has the characteristics of high viscosity and volatile. Combined with the applicability of the foam-mat drying and the characteristics of the dehydrated sludge, the foam-mat drying of the dehydrated sludge has a high research and application value.

Lignin fibers are organic fibers made from natural wood after chemical treatment, which has good toughness, dispersion and chemical stability, water absorption ability is strong, has very excellent thickening crack resistance performance[6]. Mixing the residual sludge with lignin can not only improve the calorific value, but also improve the subsequent dewatering performance of the sludge. Industrial lignin fibers FB-500 and FH-500 were collected as conditioners to investigate their effectiveness of improving sludge foamability. In this study, the method of foam-mat drying was applied to the treatment of dehydrated sludge, and the foaming and drying property of dehydrated sludge were mainly investigated.

\section{Methods and materials}

\subsection{Activated sludge}

The dewatered sewage sludge was obtained from a local municipal WWTP in Changsha, China. This plant treats $200,000 \mathrm{~m}^{3} / \mathrm{d}$ of wastewater (almost all domestic sewage) using the oxidation ditch process. Sludge was dewatered by belt filter presses with addition of cationic flocculating agents. The moisture content of dewatered sludge was $84.0 \%$, and the density was $1.05 \mathrm{~g} / \mathrm{cm}^{3}$.

\subsection{Foam formation}

The dewatered sludge was premixed with alkali and industrial fiber in a portable cement mixer (JS140, JISHUN, China) at a rotation speed of $20 \mathrm{rpm}$ for $30 \mathrm{~min}$. The textures of dewatered sludge then changed from block mass to slurry flow with more homogeneous properties. The foam formation was conducted by whipping the premixed sludge using a cement mortar mixer (JJ-5, JIANYI, China)

\footnotetext{
${ }^{a}$ Corresponding author: chenliang6662021@163.com
} 


\subsection{Sludge pretreatment process}

A series of contrast experiments was carried out between the addition of $\mathrm{CaO}$ and other sludge pretreatment methods including the addition of $\mathrm{NaOH}$ and lignin. The heating pretreatment was operated in an autoclave for temperatures ranging from $60^{\circ} \mathrm{C}$ to $120{ }^{\circ} \mathrm{C}$ with $20^{\circ}$ Cincrements for $15 \mathrm{~min}$.

\subsection{Sludge foam image capture}

A certain amount of sludge amplified by microbubbles was taken and evenly placed in the groove of the glass slide with grooves. Then, the cover glass was used to compaction and wipe off the edge of the microbubbles to amplify the sludge. The depth of the groove of the glass slide was $1 \mathrm{~mm}$. Select an electron microscope that can hold a digital camera and place the digital camera in the eyepiece of the electron microscope. The produced glass slides were placed under an electron microscope, the magnification of the objective lens (generally 40-80 times) and aperture were adjusted well, then the photos of sludge amplified by microbubbles at different periods were taken by the microscope with a digital camera.

\subsection{Sludge property analysis}

Sludge density was determined by the mean ratio of measured weight using one conical measuring cylinder with the full-loaded water weight of $206.6 \mathrm{~g}$. The moisture content of sludge was determined by the mass loss after drying at $105^{\circ} \mathrm{C}$ for $2 \mathrm{~h}$.

\section{Results and Discussion}

\subsection{Effect of $\mathrm{NaOH}$ dosage on sludge foam density}

The foamability can be evaluated by the measurement of the foam density. During the whipping process, a lower foam density indicates that more air is entrapped in the sludge foam. Figure 1 showed the change of sludge foam density with different $\mathrm{NaOH}$ dosage under the same environmental factors. According to Fig. 1, the sludge foam density gradually decreased with the increased of $\mathrm{NaOH}$ dosage. Alkali pretreatment could disrupt the microorganism cell and change the water moleculesorganic matter bonding. Meanwhile, alkaline pretreatment weakening the water retention capacity of sludge and changing more water from bound type into free type[7]. The density decreased with the accumulation of time. But when the density decreased to a certain value, it remained a stable state. It can be seen from the figure that the curves of $0.5 \mathrm{wt} \%$ and $1.0 \mathrm{wt} \%$ were similar with the curve without $\mathrm{NaOH}$, indicating that the dosage at this time did not cause sludge foaming. When the $\mathrm{NaOH}$ dosage was $1.5 \mathrm{wt} \%$, there was a trend of density decrease, which was not obvious, indicating that the sludge had foamed but was not stable. When the dosage was $2.0 \mathrm{wt} \%$, the sludge density curve showed an obvious downward trend, indicating that the sludge reached stable foaming at this time. At the beginning, the reduction rate of sludge density was basically constant, and when the density reaches a certain value, it no longer changed significantly and the tends to be stable. At this point, the air volume in the sludge amplified by microbubbles was basically saturated, and no more air can be dissolved in, so the density of the sludge amplified by microbubbles will not change significantly. Further, in terms of the highest decreasing rate of sludge foam density, the optimal $\mathrm{NaOH}$ addition was found at $2.5 \mathrm{wt} \%$ which was low enough to avoid mass increase for the further disposal of sludge.

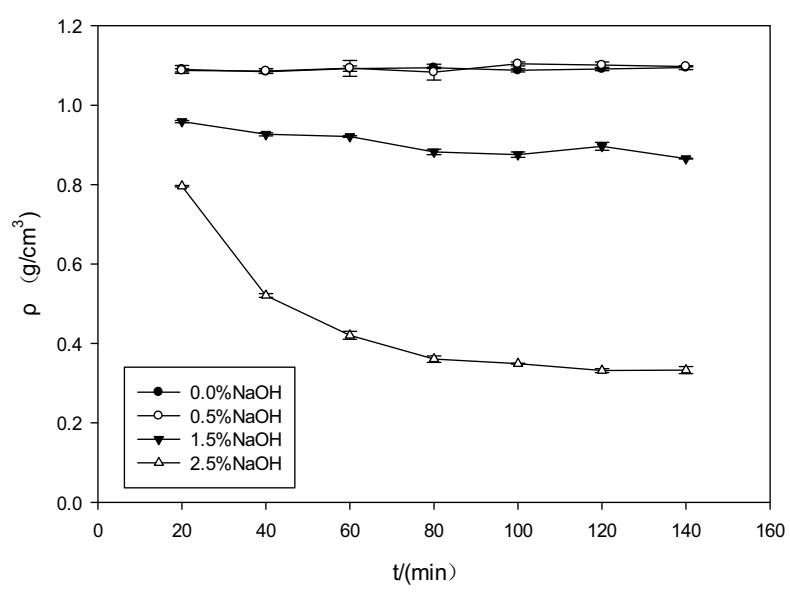

Figure 1. Effect of $\mathrm{NaOH}$ dosage on foam density

\subsection{Effect of $\mathrm{CaO}$ dosage on sludge foam density}

Figure 2 showed the change of sludge density with different $\mathrm{CaO}$ dosage under the same environmental conditions. As seen from Figure 2, under different $\mathrm{CaO}$ dosage, change rule of sludge foaming was not obvious. The overall trend of sludge density was increased first and then decreased, but the range was not very large, which indicated that it did not reach the phenomenon of sludge foaming. According to the mechanism of sludge foaming, $\mathrm{CaO}$ is an alkaline reagent, provided the alkaline condition environment for sludge, which could disrupt the microorganism cell and change the water moleculesorganic matter bonding. With the air kept coming in, sludge bubble phenomenon was more obvious. Comparing the foaming samples shown in Fig. 1, the sludge of $\mathrm{NaOH}$ pretreatment has a greater foamability than the $\mathrm{CaO}$ pretreatment. However, a lower density of sludge foam does not always imply a shorter drying time in the same drying condition. Therefore, there are many factors that affect the error of the experimental results, whether it is the experimental operation problem of the experimenter itself, or the nature of the sludge used and the differences in the instruments used, all of which will affect the experimental results[8]. 


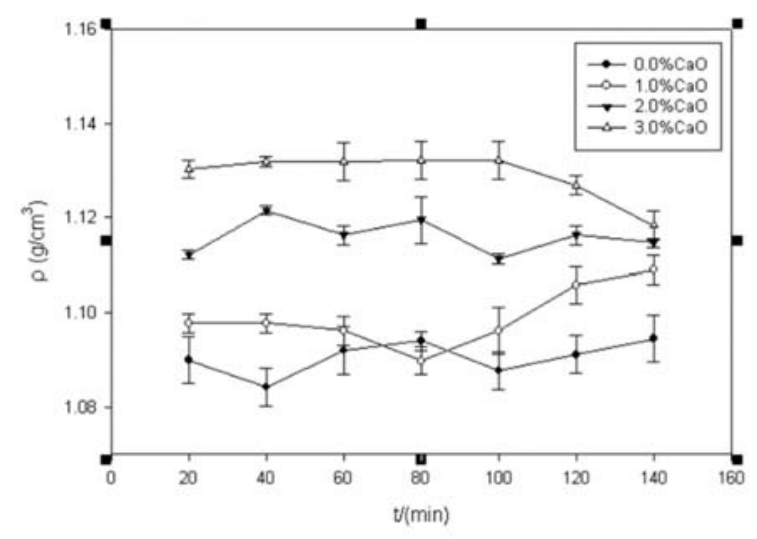

Figure 2. Effect of $\mathrm{CaO}$ dosage on sludge foam density

\subsection{Improvement of sludge foamability with industrial fiber and $\mathrm{NaOH}$}

\subsubsection{Effect of FB-500 dosage on sludge foam density}

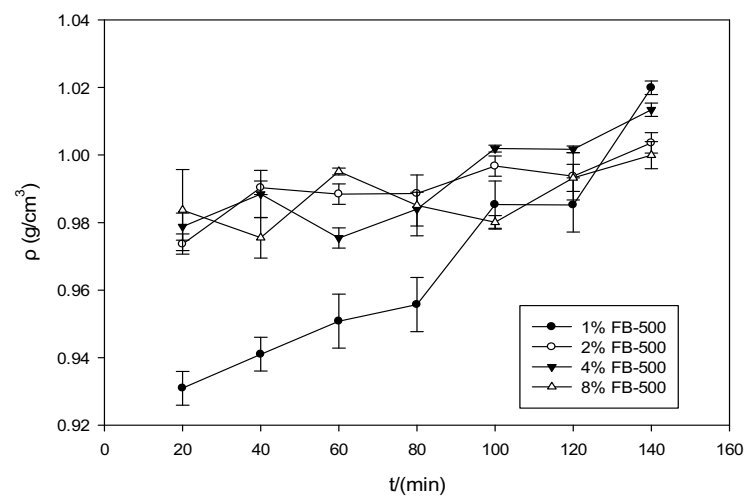

Figure 3. Effect of FB-500 dosage on sludge foam density in $\mathrm{FB}+1 \% \mathrm{NaOH}$ system

100 g sludge, $1 \mathrm{wt} \% \mathrm{NaOH}$ and a certain amount of industrial fiber FB-500 were mixed in a portable cement mixer. First, rotate slowly for $5 \mathrm{~min}$ to make the $\mathrm{NaOH}$, FB-500 and sludge mix evenly. Then, adjusted the rotating speed to high speed for $20 \mathrm{~min}$, and finally weighed the mass with the measuring cylinder and calculated the density. As shown from figure 3 , the density curves of the sludge density all increased with the extension of the stirring time. When the dosage was $1 \% \mathrm{NaOH}+1 \% \mathrm{FB}-500$, the density of sludge changed most obviously. When the addition was $1 \% \mathrm{NaOH}+2 \%$ FB-500, the change curve of sludge density was the most stable. But in general, the effectivity of FB-500 did not achieve the expectation, the density of sludge all increased.

\subsubsection{Effect of FH-500 dosage on sludge foam density}

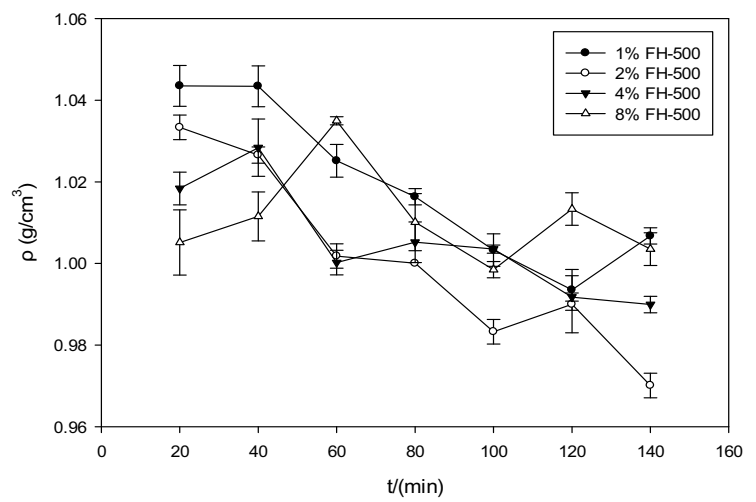

Figure 4. Effect of $\mathrm{FH}-500$ dosage on sludge foam density in $\mathrm{FB}+1 \% \mathrm{NaOH}$ system

As shown in Figure 4, the density curves of the sludge density all decreased gradually with the extension of the stirring time. The density curve of $1 \% \mathrm{NaOH}+8 \% \mathrm{FH}-500$ did not change significantly and was irregular. For the addition was $1 \% \mathrm{NaOH}+1 \% \mathrm{FH}-500$, the trend of the sludge curve declined sharply, which effectivity of foamability was better than FB-500 experiment group. From what has been discussed above, different types of industrial fiber had significant different effects on the water absorption performance of sludge. Along with the increase in concentration of suitable industrial fibers, the density could be more decreased, due to the volume of sludge was also reduced, so sludge ratio decreased relatively. But with the increase of mixing time, the mixture of sludge and industrial fibers was more uniform, when the mixing time up to $140 \mathrm{~min}$, the volume of sludge and industrial fibers proportion difference was not obvious. As shown in figure 4, the optimum dosage was $1 \% \mathrm{NaOH}+2 \% \mathrm{FH}-500$, that obtained enough low sludge density and avoided excess quantity of addition.

\subsection{Sludge foaming stability}

It is generally believed that the stability of foam is closely related to the diameter and number of bubbles in the formation of foam. The stability of smaller diameter bubbles is stronger than that of larger diameter bubbles. At the same time, the smaller the number of bubbles, the more uniform the diameter distribution, and the better the stability of the foam. The thermal stability of the sludge foam amplified by micro-bubbles was studied by observing the micro-rupture of the foam. The photos of the sludge amplified by micro-bubbles without treatment and after treatment were shown in Figure 5. 

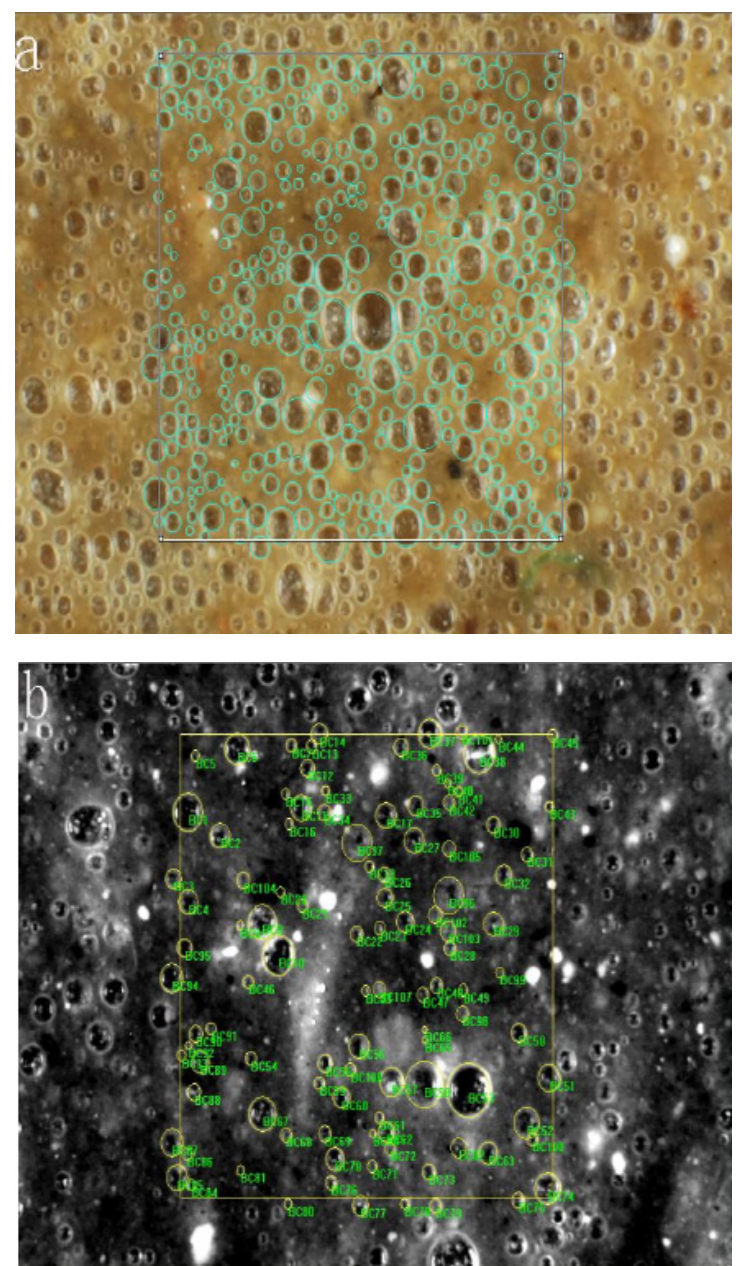

Figure 5. Photograph of microbubble amplified sludge:(a) no microbubble amplified sludge; (b) microbubble amplified sludge

\section{Conclusion}

In this study, alkali and industrial lignin fiber addition followed by mechanical whipping was employed for foaming the dewatered sludge. Using alkali alone as foaming agent, the optimal $\mathrm{NaOH}$ addition was found at $2.5 \mathrm{wt} \%$, which was superior to adding $\mathrm{CaO}$. Considering the maximum foaming efficiency, $2 \%$ industrial lignin fiber FH-300 collected as a conditioner and $1 \% \mathrm{NaOH}$ was optimal. The foams in dewatered sludge were highly stable. The total number of bubbles of sludge with different densities had big differences. The diameters of bubbles concentrated on the range of $0.1 \mathrm{~mm}-0.3 \mathrm{~mm}$. Overall, an appropriate foaming pretreatment provides a larger evaporation surface, increases the effective water diffusion coefficient of the sludge, which significantly improves the subsequent sludge drying performance.

\section{Acknowledgments}

This work was financially supported by the National Natural Science Foundation of China (5180821 6), Natural Science Foundation of Hunan of China(2020JJ4643), the Research Project of Education Department of Hunan Province of China (18B406),
Science and Technology International Cooperation Proje ct of Changsha City (KQ1907082).

\section{References}

1. X. Li, F. Li, C. Lai, J.H. Huang, Y. Pang, K. Luo, X.S. Liao, J. Cent. South Univ. 24, 1953(2017)

2. F.Li. Y. L. Wang, J.D. Zhang, Y. C. Lu, X. Zhu, X.Y. Chen, J.J. Yan, J. Clean Prod. 275, 12431(2020)

3. S. Ido, B. Markus, Biosyst. Eng. 24, 1353(2006)

4. B.H. Guan, J. Yu, H.L. Fu, Water Res. 46, 425(2012)

5. C. Ratti, T. Kudra, Dry. Technol. 24, 1101(2006)

6. A.R. Celma, F. Cuadros, Food Bioprod. Process. 90, 224(2012)

7. J. Huang, Z.H. Yang, G.M. Zeng, H.L. Wang, J.W. Yan, H.Y. Xu, C.L. Gou, Water Res. 68, 667(2015)

8. H.L. Wang, Z.H. Yang, J. Huang, L.K. Wang, C.L. Gou, J.W. Yan, J. Yang, Water Sci. Technol. 69, 1859(2014) 